\title{
The financial risk index system and early-warning research
}

\author{
ZHU Honghan, LIU Xiangyun \\ Finance department, Guangdong University of Finance and Economics, luntou road, No. 21, \\ Huizhou district, Guangzhou City, Guangdong Province,China
}

676701320@qq.com

\begin{abstract}
Keywords:financial risk; neural network model;early warning mechanism
Abstract.Establishment and optimization of system and the early warning system of financial risk index model were the hot issues in the research of financial risk management. Research institutions and government agencies cooperation made economic early warning methods gradually mature and application. Through the research on the financial risk index system and early-warning model and summarizes, it could accurately measure the economic indicatorsto deal with the financial risk early warning. The use of artificial intelligence technology method, the application of Internet and data analysis and information technology in the financial risk index system and early-warning study could resolve the traditional model's ability to handle the problem of insufficient qualitative indexes, and improved the adaptive ability of the system, the intelligent information processing technology, economic early warning model constructed by combining financial risk early warning system had become a hot and new research directions.
\end{abstract}

\section{Introduction}

The 1888 Paris statistics Congress put forward using different colors as the economic evaluation of state papers, marked the beginning of research on economic early warning methods.In twentieth Century,continuous improvement and development began to enter the practical period. In 1937, the US National Bureau of economic research chose 21 indexes advanced index, system detailed study of a series of problems involving Prosperity Monitoring method. In 1961, the U. S. Department of Commerce official in its publication provided macro trend of the signal to make economic early warning methods gradually mature. The financial risk index system and early-warning research hadthe following characteristics: it made great progress in the basic method of economic early warningin the aspect of research on information recognition. The basic theory was still in continuous development. The application of Internet and large data and other information technology in the financial risk early warning index system solved the problem of insufficient qualitative indexesimproved the adaptability of the system, so the new data could play a vitalrole in system modeling[1].

\section{Financial risk,the financial crisis,contagion effect}

Systemic financial risk could be accumulated according to certain criteria. The financial crisis was a concrete implementation of the system of risk probability used the financial crisis as the conversion of financial risks. Put forward the first generation monetary crisis model,Krugman thought that the root of payment crisis was the use of country fixed exchange rate or the pegged exchange rate system of government, to avoid the maintenance of our currency and lead to domestic inflation, so that the local currency depreciated significantlythe final payment crises [2]. 
Frederic argued that the financial crisis was that the innate moral risk and reverse choice became too serious, so that the production efficiency between the financial market and misallocation of resources would lead the collapse of financial markets [3]. Most of the financial indicators deteriorated sharply, with all kinds of financial assets prices and the phenomenon of financial institutions bankruptcy. The financial crisis in the economic cycle, the capital flow between the main body of financial market and asset price abnormal fluctuation,market information transmission and interactive, the abnormal fluctuation of each department conducted the economy, resulting in the increasingly open economic conditions, local departments economic indicators continue and volatile phenomenon. If the connotation to the full measure of the financial crisis, must from the financial system, the inherent risks of outer factors of financial system, financial crisis, financial crisis evolution characteristics of the comprehensive and dynamic angles to study[4].

Kandinsky and Reinhart emphasized the crisis contagion country contagion and the causality between the countries, crisis contagion effect: a crisis in one country would cause the probability of another country's crisis. Infectious disease experts pointed out: infection was a disease, emphasized the diffusion degree of crisis. According to the crisis contagion, contagion was divided into two types: the first was a worldwide crisis contagion. The second was the national crisis [5].

\section{The index system and method of financial risk}

The key was how to choose the scientific warning indicators and warning method of early warning system. Financial crisis early warning methods were mainly KLR model Kumar and Perraudinlagged macroeconomic and financial data model. Each kind of early warning methodwas applicable premise and the hypothesis had its advantages and disadvantages. The effect of crisis early warning model selection method had great relations. The practical application of relatively good effect was mainly KLR model. Many scholars devoted to the early warning mechanism of financial crisis, such as Chen XueJun analyzed six kinds of empirical calculation model and application of existing foreign exchange market pressure index.Analyzed the status and the degree of early warning model of the use of foreign on China's financial security and financial crisis were the limitations of monitoring.

In the existing financial crisis early warning model research results, affecting a wide range, strong operability and widely recognized: Frankel and Rose had proposed FR probability model; Sachsand Velasco had established the cross-section regression model. Kaminsky and Reinhart created a KLR model.Some scholars mainlyfocused the index system, index introduction method, innovated the definition of crisis or to test the effectiveness of several aspects[6].

\section{Business climate index method}

The ARMR model also known as autoregressive moving average models, it was a put forward by Bakes and Jenkins. The time series model is generated by stationary random process with a zero mean. The value of diffusion index in t time

$$
D I_{t}=\sum_{i=1}^{I} w_{i} I\left[x_{i t}>x_{i, t-1}\right] \times 100
$$

Among them: $\left\{x_{i t}\right\}$ The index system of the pre processed, $w$ As the weights, $I$ for the indicator function.Synthetic index not only can predict the turning point in the economic cycle, but also reflect the economic cycle fluctuation amplitude. 


\section{ARCH model}

The ARCH model, namely the autoregressive conditional model, it statistically provided a method to explain the future past error prediction error.Assuming that $\left\{\mathrm{y}_{t}\right\}$ is the observation sequence, $\mathrm{J}_{t}$ is a limited set of information until the t time, the general linear ARCH (q) model

$$
\begin{gathered}
Y_{t}=b X_{t}+X_{t} \\
X_{t} / \mathrm{J}_{t-1}: N\left(0, \mathrm{e}_{t}^{2}\right) \\
\mathrm{e}^{t 2}=T_{0}+T_{1} X_{t-1}^{2}+T_{2} X_{t-2}^{2}+\cdots+T_{q} X_{t-q}^{2}
\end{gathered}
$$

The method introduced a time-varying conditional variance, so that confidence intervals could reflect the different periods of the size of the forecast errors, thereby enabled the determination of the warning could accurately reflect the actual economic situation [7].

\section{Neural network model}

Artificial neural network model was a mathematical model of simulation analysis of the mode of thinking of human brain. The main idea: for input sample $p^{1}, p^{2}, \cdots p^{m}$, the corresponding output sample $q^{1}, q^{2}, \cdots \mathrm{q}^{l}$, the purpose of the study was to make the error network actual output $R^{1}, R^{2}, \cdots R^{l}$ and target output $q^{1}, q^{2}, \cdots \mathrm{q}^{l}$ between the modified weights, make $q^{1}, q^{2}, \cdots \mathrm{q}^{l}$ and $R^{1}, R^{2}, \cdots R^{l}$ as close as possible, error square to minimum. The relationship between the input and output of a neuron to:

$$
q_{1}^{n}=f_{1}\left(\sum_{m=1}^{m} w_{m n} p^{m}+\varepsilon_{m}\right)
$$

The relationship between input and output of neurons in the output layer:

$$
\mathrm{q}_{2}^{l}=f_{2}\left(\sum_{n=1}^{n} w_{n l} q_{1}^{n}+\varepsilon_{n}\right)
$$

The representation of the learning speed, which can be further expressed as:

$$
\eta=\frac{k}{\sqrt{\sum\left(\frac{\partial E}{\partial \alpha}\right)^{2}}}
$$


The input data and output sample data continue train the neural network, the spread of each layer weight change and error was obtained by gradient descent method, when the network training error reached a predetermined target at the end. Since the gradient method to calculate the speed was relatively slow, the hybrid algorithm of gradient method and the least square algorithm could calculate the speed to a certain extent improve network. After training the network weights, continuous learning could be a variety of prediction analysis [8].

\section{The application of neural network model}

When given a large number of sample data and network structure, neural network models often exist over fitting problem. Based on adaptive neural network learning method, gradient calculation speed was slow and easy to fall into local minimization problem. But the neural network model without assuming strict, artificial neural network could realize the information memory, while the memory information was stored in the weights. From a single weight, distributed storage mode made the network good fault tolerance. The model of learning ability was very strong, artificial neural network could get the weight and structure of the Internet through training and learning to adjust its weights of the ability to adapt external changes. According to the research of scholars and the results proved that the neural network model had good accuracy and stability in forecasting, especially in the short term prediction on the more obvious advantages.

\section{Summary}

Economic early-warning was based on prediction technology, and thenthe results had the deviation with the reality.If the error alarm, would cause some economic loss. And the probability of false alarm and the probability of false alarm to determine the current still have no scientific estimation method, thus warning reliability was still one of the problems to be further studied.

Information technology provided a powerful tool for the development of early warning system. Make full use of modern computer technology, the development of practical advanced software, made theeconomic early warning system had man-machine interface. The multimedia technology into the early warning system, realized the dynamic display of the alarm, warning results more rich. Artificial neural network technology had been applied to the early warning system, based fuzzy reasoning, rule-based reasoning and chaos theory. It neededfurther research to the early-warning support system and expert system more closely together.

\section{Acknowledgements}

The research work was supported by the national natural science foundation of china(NSFC) under Grant No. 71273067 and the planning projects of humanities and social science ministry of educatio n under Grant No. 11YJA790089.

\section{References}

[1]HengS, Meyer T, andStobbe A.Implications of Web 2.0 for Financial Institutions2007, pp.14-18

[2]EverettC.R. Group membership, relationship banking and loan default risk: The case of online social lending .Social Science Research Network, No.18(2008) 
[3]Seth Freedman, Ginger ZheJin."Do Social Networks Solve Information Problems for Peer-to-Peer Lending? Evidence from Prosper.com," Working Paper University of Maryland \& NBER, 2008 p.87

[4]Agarwal,S., and Hauswald,R.Social Science Research Network, November 24, 2008.

[5]Lepro, Sara, "The Price of Entry Rises in P2P Lending .American Banker", 2010 No.39

[6]Weiss,GN.,Pelger,K.,andHorsch,A. "Mitigating adverse selection in P2P lending: Empirical evidence from Prosper.com.TUDortmund,Germany", 2010 p.432

[7]Alexander Bachmann, Alexander Becker. Online Peer-to-Peer Lending - A Literature Review . JIBC August 2011 p.143

[8]Boivin J. Sticky Prices and Monetary Policy:Evidence from Disaggregated US Data, American Economic Review, 2009, pp.350-384. 